\title{
Experimental Investigation of Impulse Characteristics of Transmission Line Tower Footings
}

\author{
N. Harid", H. Griffiths, N. Ullah, M. Ahmeda and A. Haddad
}

High Voltage Energy Systems Group, School of Engineering, Cardiff University, the Parade, Cardiff CF24 3AA, UK

\begin{abstract}
Understanding the impulse response of tower grounding systems is a key factor in the determination of the lightning performance of transmission lines and the safety voltages near high voltage towers. This paper reports the results of an experimental study on the impulse characteristics of full-scale transmission line tower footings. The ground potential distribution both at the ground surface and below ground was examined under impulse currents and variable-frequency AC currents. Prospective impulse step and touch voltages were determined by measurement of the ground surface potential distribution near the tower base. The behaviour of the impulse resistance of the tower footings under highmagnitude impulse currents was investigated. The non-linear characteristics of the impulse resistance with peak current are demonstrated for the entire tower base and for single tower footings. The soil ionisation inception is found to be dependent on the rate of rise of applied current. The dynamic impulse resistance was used to describe the dynamics of soil ionisation.
\end{abstract}

Keywords: Grounding, impulse resistance, transmission line towers, ground potential, soil ionisation, lightning, step voltage, touch voltage.

\section{INTRODUCTION}

The ground resistance of tower base footings affects lightning outage rates on transmission and distribution lines and also the ground potential rise at towers during ground faults. Following a lightning stroke to a tower, high currents flow into the ground through the tower footings, giving rise to soil ionisation and thermal effects. As a result, the ground resistance of the tower base decreases by an amount which depends on soil resistivity, the current magnitude and the tower footings construction. For power system operation, it is desirable that this resistance has a low value to prevent line backflashover and maintain the ground potential rise within safety tolerance limits. In some cases, additional electrodes or grading loops are buried near the tower to control the ground potential distribution and reduce the tower ground resistance.

Several investigations related to the impulse characteristics of tower grounding and concentrated ground electrodes have been reported in the literature [1-6]. Of the parameters characterising the impulse behaviour of grounding systems, the impulse resistance is of most significance; it is dependent on electrode geometry, earth resistivity, peak value and rate of rise of impulse current. Most published work relate to experiments carried out on reduced-scale ground electrodes in a laboratory environment. Such experiments have the advantage of controlled conditions; however, there is uncertainty as to whether they can be reliably extrapolated to replicate full-scale grounding system behaviour. Several models that have been proposed

*Address correspondence to this author at the High Voltage Energy Systems Group, School of Engineering, Cardiff University, the Parade, Cardiff CF24 3AA, UK; Tel: +44 (0)29 20875351; Fax: +44 (0)29 20874716;

E-mail: Haridn@Cardiff.ac.uk to account for soil ionisation and non-linear thermal effects [7-11] rely on these experiments for validation. However, field experiments on full-scale grounding systems offer a more realistic way of validating model computations because of their unbounded environment and non-uniform soil conditions.

This paper reports the results of experiments carried out on a full-scale $275 \mathrm{kV}$ tower base installed in non-uniform soil. Initial work on this tower base was reported by the authors $[5,6]$. In this present work, the results of tests with an extended range of impulse current magnitudes are described, using an improved ring electrode system as a return current electrode.

First, the low-current impulse and dc ground resistance of the tower footings and the return current electrode are measured and compared with calculated values. Also, the impulse ground potentials near the tower base were measured and compared with those obtained under ac voltages. Such measurements can be used to evaluate the prospective step and touch voltages developing near highvoltage towers during lightning strikes. In addition, the potentials at different depths in the concrete and in the soil surrounding tower footings were measured to help clarify the potential distribution with depth.

With the high-current impulse tests, the measurement results are analysed to show the non-linear effect of soil ionisation. The dynamic impedance defined by the ratio $v(t) / i(t)$ and the variations of impedance with applied current were examined.

\section{DESCRIPTION OF THE TEST CIRCUIT}

\subsection{Tower Footing Dimensions}

The tower base consists of four concrete-embedded steel footings forming a $7.25 \mathrm{~m} \times 7.25 \mathrm{~m}$ square, each buried to a 
depth of $3 \mathrm{~m}$. These footings were installed several years prior to commencing the tests which allowed the soil to completely settle around the concrete. The details of the tower footing geometry and dimensions with the surrounding concrete are shown in Fig. (1).

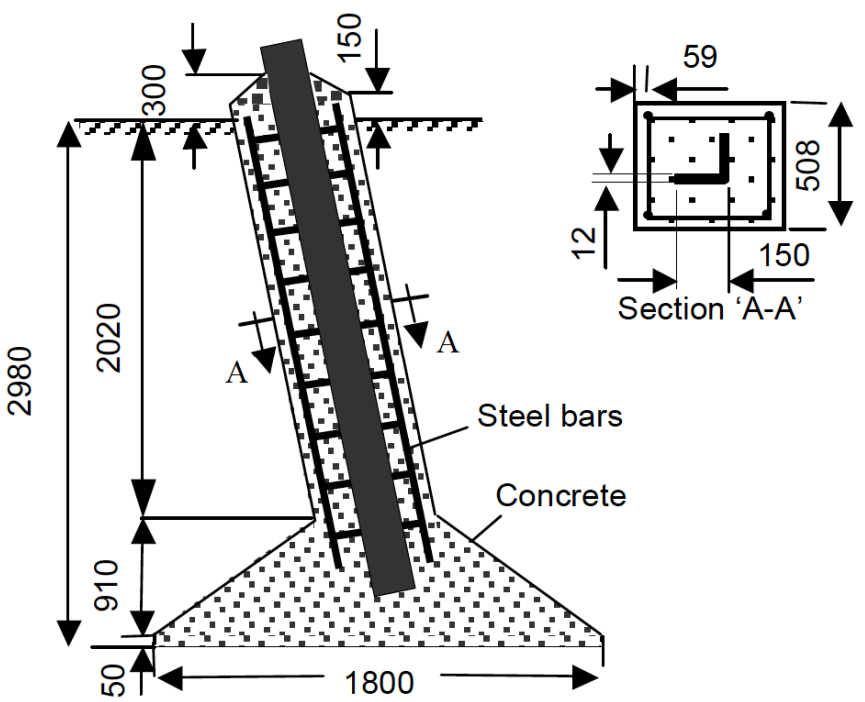

Fig. (1). Tower footing geometry (not to scale), all dimensions in $\mathrm{mm}$.

\subsection{Experimental Arrangement with New Ring Electrode System}

The experimental setup adopted here is shown in Fig. (2). An impulse generator rated $20 \mathrm{~kJ}, 20 \mathrm{kA}$ was used to inject impulse currents into the test electrode through a $30 \mathrm{~m}$ overhead line consisting of a bundle of two $30 \mathrm{~m}$-long insulated copper wires, supported by $1.7 \mathrm{~m}$-high wood poles (Fig. 2a). The voltage measurement line is a single conductor supported by similar wood poles, in a direction orthogonal to the current injection line to minimize inductive coupling. The current return electrode consists of a $60 \mathrm{~m}-$ diameter ring electrode connected to eight $16 \mathrm{~mm}$-diameter rods (Fig. 2b). The rods are driven to a depth of $2.4 \mathrm{~m}$ and the ring is buried at a depth of $0.3 \mathrm{~m}$. This arrangement with ring electrode is believed to replicate more realistically the current distribution in the soil around the tower base during lightning strikes, compared with the more commonly-used single-rod return electrode arrangement. For lightning strikes on operational towers, the current in the ground distributes in all directions and returns to the system neutrals through infinite paths. Nevertheless, within a $60 \mathrm{~m}$-diameter region, the volume of earth surrounding the tower base contributes the major part of the resistance and the current in this region can be considered to flow uniformly around the tower base. For low-current tests, low-voltage impulse and variable frequency $\mathrm{AC}$ generators were used.

\subsection{Current Distribution in the Return Ring Electrode}

To justify the choice of the auxiliary current electrode, the current returning in the ring was computed using an electromagnetic field method [12]. For this purpose, the line was energised with a $5 / 23 \mu \mathrm{s}$ impulse current of $1 \mathrm{~A}$ amplitude, and the current in various sections of the ring electrode was computed. Fig. (3a) shows the results of the computed current flowing in each ring section between two adjacent rods, in percent of the total injected current. The dotted arrows indicate the directions of current flow in the ground before it is collected by the ring electrode. Fig. (3b) shows the proportion of current collected by each section of the ring between two adjacent rods. As expected, the current proportions are not uniform due to different section lengths and to non-uniformity of soil resistivity in the vicinity of the electrodes. The results also showed that the current flowing in the vertical rods was only a very small proportion of the total injected current (less than $2 \%$ ). This result was verified experimentally by measuring the current split between the ring electrode and rods at different locations.

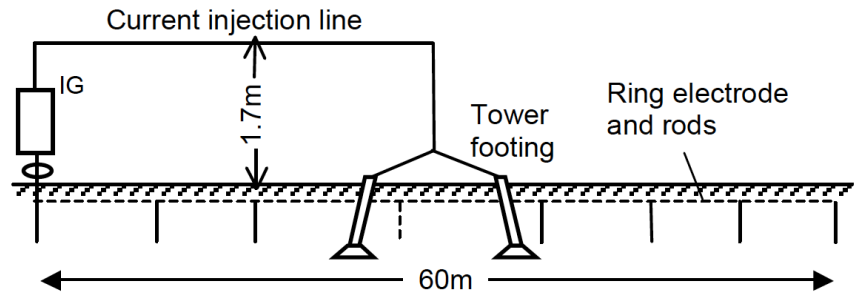

(a)

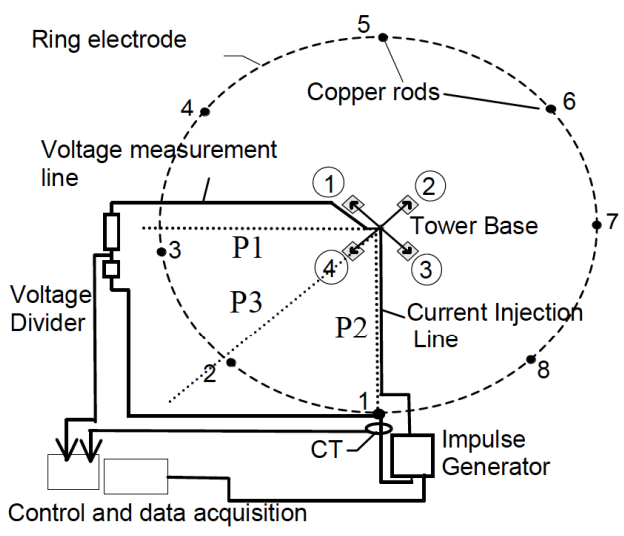

(b)

Fig. (2). Experimental set-up. Elevated view; (b) Plan view.

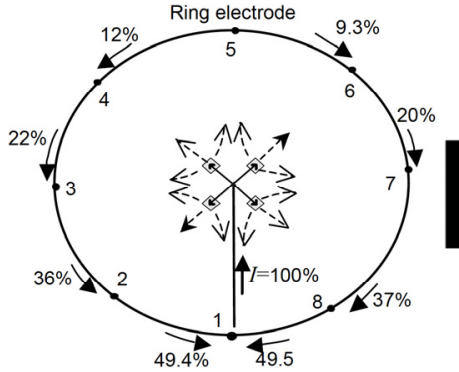

(a)

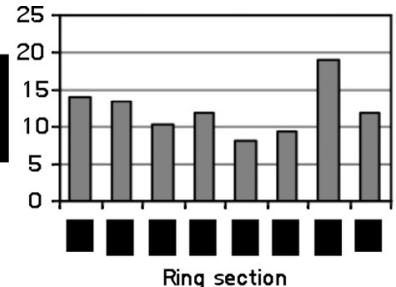

(b)
Fig. (3). Computed current distribution in the return ring electrode. (a) Current distribution in ring electrode, (b) current collected by each ring section.

\subsection{Measured Soil Resistivity at Site}

The soil resistivity was measured at the site using a method which combines both vertical imaging and horizontal profiling. The measurement equipment can be set to automatically disregard spurious readings such as negative or extremely contrasting values. The soil resistivity was found to vary laterally. Consequently, it was decided to take the average value of all measurements made at a given 
Wenner spacing. The results of apparent resistivity obtained with the Wenner configuration are shown in Fig. (4). With the help of numerical inversion, the soil at the site could be approximated by a two-layer structure consisting of a $9 \mathrm{~m}$ deep upper layer of resistivity $\rho_{I}=220 \Omega \mathrm{m}$ overlaying an infinite lower layer of resistivity $\rho_{2}=50 \Omega \mathrm{m}$. Throughout the test period, the resistivity was found to change seasonally by up to $30 \%$ as shown in Fig. (4), as a result of changes in temperature and rainfall.
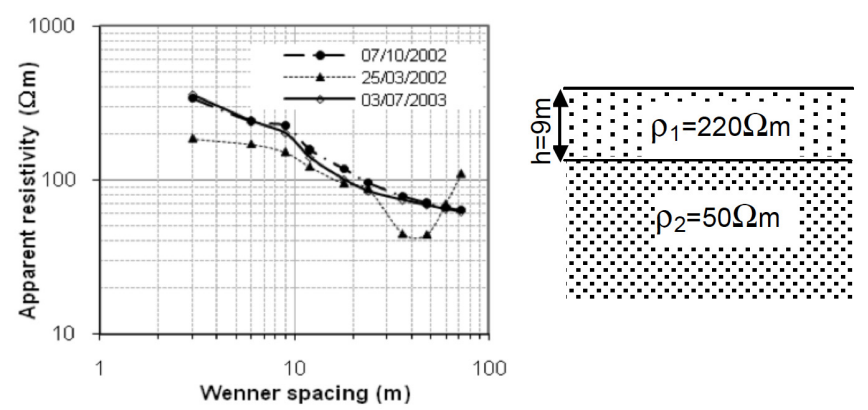

Fig. (4). Measured apparent soil resistivity and soil model.

3. DETERMINATION OF THE DC AND LOWCURRENT RESISTANCES OF TEST ELECTRODES

\subsection{Measurement of DC and Low-Current Impulse Resistance}

Initially, low-magnitude double-exponential impulse currents were applied to the tower footings and to the entire tower base, and the voltages with respect to a reference electrode placed $100 \mathrm{~m}$ away from the centre of the tower base were measured. The impulse resistance defined by the ratio

$$
R_{i m p}=\frac{V_{p}}{I_{p}}
$$

where $V_{p}$ and $I_{p}$ are the peak voltage and current respectively, was determined for each single tower footing (leg), the entire tower base and the ring electrode. The DC resistance of each test electrode was also measured and the results are shown in Table 1. The ring electrode DC ground resistance was measured using the fall-of-potential method, where another tower located at a distance of $115 \mathrm{~m}$ from the ring was used as the auxiliary current electrode. The tower footings have different resistances due to different local soil conditions, which were evident during installation. The ring electrode and peripheral rods have a low overall resistance compared with that of the tower footings, and will not considerably limit the magnitude of the test current.

\subsection{Computation of DC Resistance of Test Electrodes}

\subsubsection{Tower Footings}

The ground resistances of each tower footing $R_{i}$ can be calculated using the following formula, assuming that the footing can be represented by a cylinder of radius $r$ and length $l$ with a linear current source along its axis [13]:

For a single tower footing:

$$
R_{i}=\frac{\rho_{1}}{2 \pi l}\left[\ln \left(\frac{4 l}{r}-1\right)+\sum_{n=1}^{\infty} \frac{k^{n}}{2} \ln \frac{n h+l}{n h-l}\right]
$$

where $\rho_{l}$ is the resistivity of the top layer, $h$ its depth and $k$ the reflection coefficient given by $\left(\rho_{2^{-}}-\rho_{l}\right) /\left(\rho_{2}+\rho_{l}\right)$.

Table 1. Measured and Computed DC and Impulse Resistances of the Tower Footings, the Tower Base

\begin{tabular}{|c|c|c|c|c|c|c|c|}
\hline & & Leg1 & Leg2 & Leg3 & Leg4 & Tower Base & Ring \\
\hline \multirow{3}{*}{ 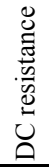 } & & $\left(R_{l}\right)$ & $\left(R_{2}\right)$ & $\left(R_{3}\right)$ & $\left(R_{4}\right)$ & $\left(R_{T}\right)$ & $\left(R_{c}\right)$ \\
\hline & Measured & 108.2 & 64.6 & 75.8 & 55.3 & 18.5 & 2.8 \\
\hline & Computed & 60 & 60 & 60 & 60 & 18.2 & 3.1 \\
\hline $\begin{array}{l}\text { U } \\
\text { E్ }\end{array}$ & \multicolumn{7}{|l|}{$\left(\mathbf{R}_{\mathrm{imp}}\right)$} \\
\hline \multirow{2}{*}{ 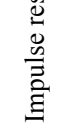 } & Measured & 109.4 & 63.9 & 75.3 & 53.9 & 18.2 & 2.71 \\
\hline & Computed & - & - & - & - & 18.3 & 3 \\
\hline
\end{tabular}
and the Return Electrode

For the tower base (4 footings in a square):

$R_{T}=R_{i} \frac{1+2.707 \alpha}{4}$, with $\alpha=\frac{\rho_{1}}{2 \pi R s}$

where $l$ is the tower footing length, $r$ its equivalent radius and $\mathrm{s}$ is the side of the square.

\subsubsection{Ring Electrode}

Since the ring electrode is buried at a small depth, the effect of the bottom layer may be neglected and the following resistance formula for a uniform soil can be used:

$$
R_{\text {ring }}=\frac{\rho_{1}}{2 \pi^{2} D}\left(\ln \frac{8 D}{d_{o}}+\ln \frac{4 D}{2 h_{o}}\right)
$$

where $D$ is the ring diameter, $h_{\mathrm{o}}$ its burial depth and $d_{\mathrm{o}}$ the diameter of the wire.

\subsubsection{Ring Electrode with Rods at its Periphery}

The following expression was used to calculate the resistance of the current return electrode, which is the combined resistance of the ring electrode and 8 rods on its periphery:

$$
R_{c}=\frac{R_{\text {ring }} \cdot R_{o}-R_{m}^{2}}{R_{\text {ring }}+R_{o}-2 R_{m}}
$$

$R_{\mathrm{o}}$ is the equivalent resistance of the rods given by:

$$
R_{o}=\frac{1}{8} \cdot\left(R_{i}+\frac{\rho 1}{2 \pi D} \sum_{k=1}^{7} \frac{1}{\sin \left(\frac{k \pi}{8}\right)}\right)
$$

$R_{i}$ is the resistance of a single rod calculated from (2) with $r=8 \mathrm{~mm}$ and $l=2.4 \mathrm{~m}$, and $R_{m}$ is the mutual resistance between the rings electrode and the rods, given by:

$$
R_{m}=\frac{\rho}{\pi^{2}} \cdot \ln \frac{4 D}{\sqrt{\frac{2 l D}{e}}}
$$


The calculated values of $R_{i}, R_{T}$ and $R_{c}$ are shown in Table 1 together with the measured values.

\subsection{Computation of Low-Current Impulse Resistance}

To compute the low-current impulse resistance of the tower base and the ring electrode, the equivalent circuit shown in Fig. (5) was used, representing the low-current impulse tests. The tower base is modelled as a parallel combination of four impedances $Z_{i}$, connected in series with impedance $\left(Z_{c}\right)$ representing the return electrode. Both $Z_{i}$ and $Z_{c}$ consist of a resistance $\left(R_{i}, R_{c}\right)$ in series with an inductance $\left(L_{i}, L_{c}\right)$ respectively. The inductance $L_{\text {line }}$ and capacitance $C_{\text {line }}$ of the current injection line are also included in the circuit. The capacitive components of the tower legs and the perimeter rods have been neglected as they are very small compared with the resistive components.

In this model, the resistances $R_{i}$ and $R_{c}$ were taken equal to the measured values shown in Table 1 . The inductances $L_{i}$ and $L_{c}$ were calculated using the following formulae for vertical rod and horizontal electrode respectively:

$$
\begin{aligned}
L_{i} & =\frac{\mu_{o} l}{2 \pi}\left(\ln \frac{4 l}{r}-1\right) \\
L_{c} & =\frac{\mu_{o} l}{2 \pi}\left(\ln \frac{2 \pi D}{\sqrt{d_{o} h_{o}}}-1\right)
\end{aligned}
$$

The source current was obtained by a double-exponential approximation of the actual measured current as shown in (Fig. 6a). The resulting tower base voltage is shown in Fig. (6b). As can be seen in this figure, the computed voltage is in agreement with the measured voltage, particularly the wave front and peak value. The impulse resistances determined from the equivalent circuit results are $18.3 \Omega$ for the tower base and $3 \Omega$ for the return electrode, and are similar to the DC resistances. The same procedure can be applied to compute the impulse resistance of each isolated tower footing.

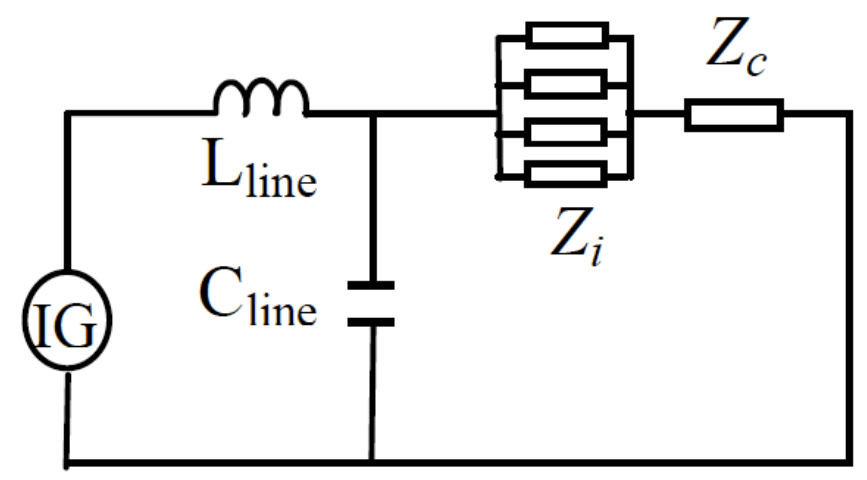

Fig. (5). Equivalent circuit of low-current measurement set-up.

\section{HIGH-CURRENT IMPULSE TEST RESULTS}

\subsection{Variation of Impulse Resistance with Current Magnitude}

Impulse currents of $4.5 / 13 \mu$ s shape with magnitudes between $0.5 \mathrm{kA}$ and $10 \mathrm{kA}$ were injected into the entire tower base. Fig. (7) shows selected recordings of injected currents and corresponding tower base ground potential rise measured with reference to the ring electrode. The ratio $V_{p} / I_{p}$, used to characterize the impulse resistance, is mainly indicative of the tower base characteristic since the current return electrode resistance is much smaller than that of the tower footings.

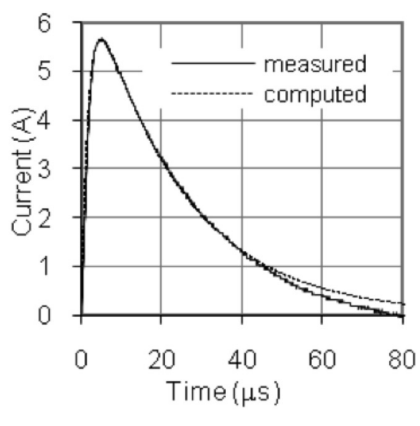

(a) injected current

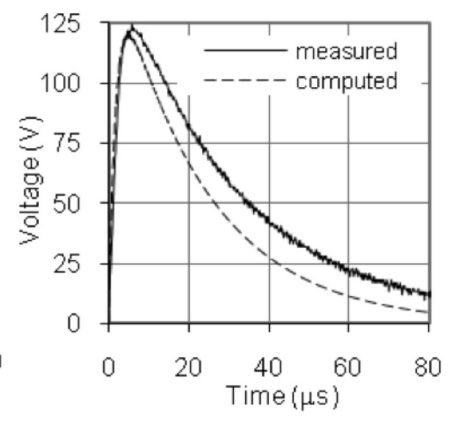

(b) tower base voltage
Fig. (6). Computed and measured low current impulse voltage.

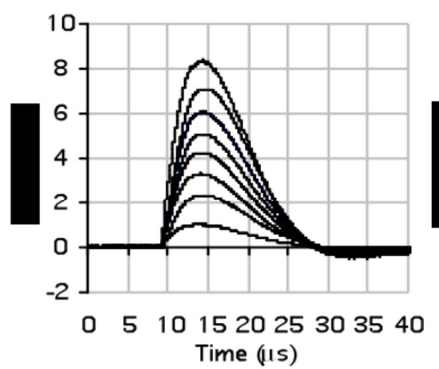

(a)

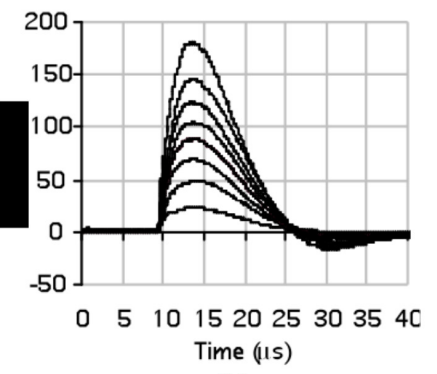

(b)
Fig. (7). Measured (a) impulse currents and (b) corresponding tower base impulse voltages.

Because the tower footings have different DC and lowmagnitude impulse resistances, it was decided to investigate the impulse characteristics of each tower footing in addition to that of the full tower base. Figs. $(\mathbf{8}, 9)$ show the variations of impulse resistance with peak current for the entire tower base and for single tower footings respectively. A relatively small reduction of about $12 \%$ in the tower base impulse resistance occurs over the range of injected current. For single tower footings, when the current increases from 500A to $6 \mathrm{kA}$, the impulse resistances decreased by $47 \%$ for tower footing No1, $40 \%$ for tower footing No3, $22 \%$ for tower footing No2 and $14 \%$ for tower footing No4, indicating that the highest reduction in resistance occurs with the footing having the highest $\mathrm{DC}$ resistance.

As is well known, soil ionisation is more likely to occur with electrodes of small surface area, high currents and in high-resistivity soil. This was verified by the authors of [3] in an experimental study on a $500 \mathrm{kV}$ tower base, which showed that the decrease in tower base resistance with current magnitude was hardly noticeable.

\subsection{Dynamic Impulse Impedance of Tower Footings}

Fig. (10) shows the voltage and current waveshapes and the ratio $r_{i}(t)=v(t) / i(t)$, referred to here as the dynamic impulse impedance, for two different current magnitudes applied to tower footing No1. Soil ionisation occurs mainly around the impulse peak and is characterized by an increase in current accompanied by a sharp reduction in voltage. In 


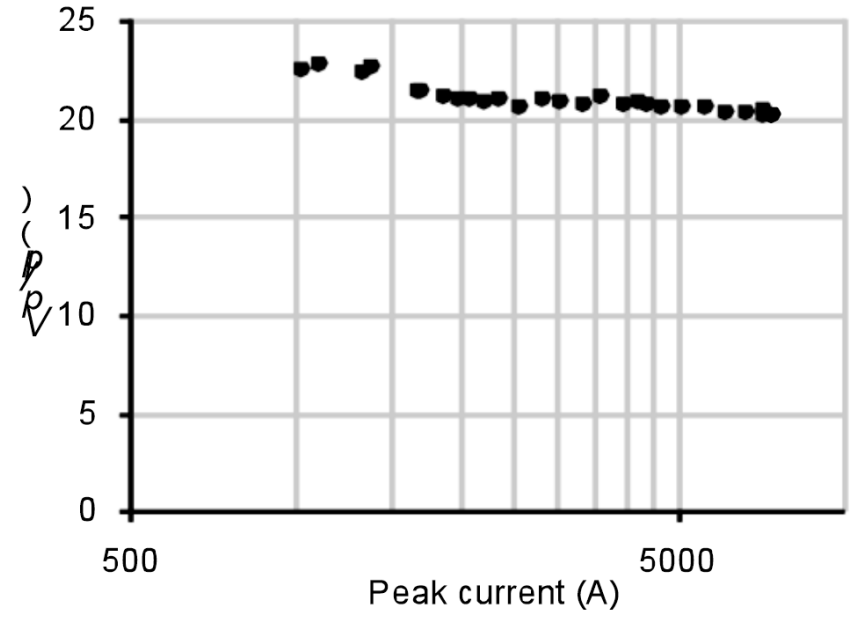

Fig. (8). Variation of tower base impulse resistance with current magnitude.

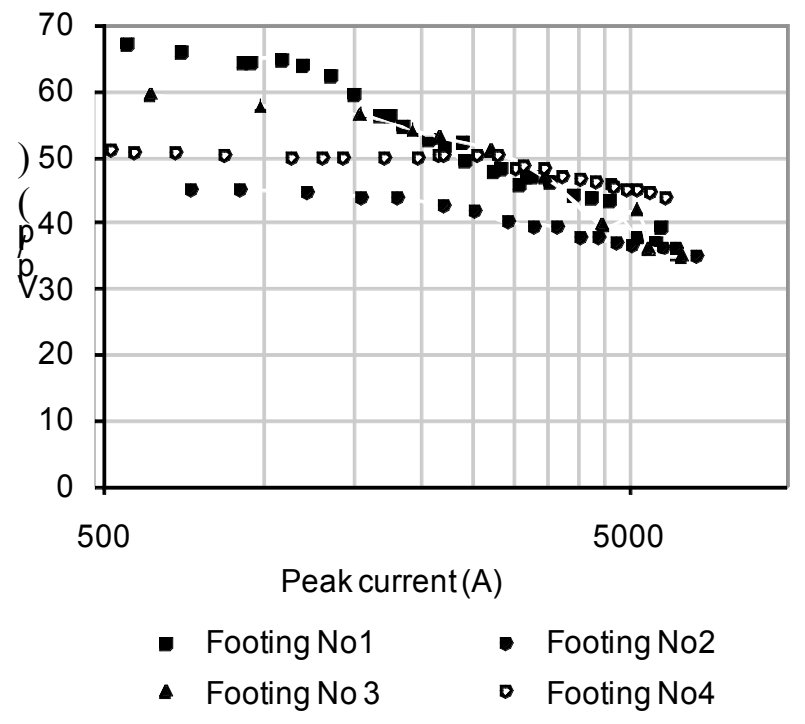

Fig. (9). Variation of impulse resistance of single tower footings with current magnitude.

Fig. (10a), the pre-ionization dynamic impedance has a value of about $100 \Omega$, which is approximately equal to the measured DC rand low-current resistance values shown in Table 1. Following ionization, the dynamic impulse impedance decreases sharply to a minimum value near the instant of current peak, then recovers slowly its lowfrequency value during the falling part of the impulse. At higher current, the dynamic impedance shows two sharp reductions; a first reduction on the rising part of the current, followed by a second reduction near current peak, as shown in Fig. (10b). These reductions are associated with multiple discharges in the soil leading to a much larger decrease in resistance.

Fig. (11) shows the variation of the dynamic impulse impedance with current for tower footings No1 and No3 and for different current magnitudes. The upper part of the curve is the pre-ionisation impedance which includes the measurement circuit inductance effects. At the onset of ionisation, the impedance falls at rate which is dependent on the applied current magnitude. In some cases ionisation activity does not completely extinguish at current peak but continues to grow for a short period after the current has reached its peak. After extinction of ionisation, the impedance recovers its original pre-ionisation value at a much slower rate. This period is known as the "deionisation" period.

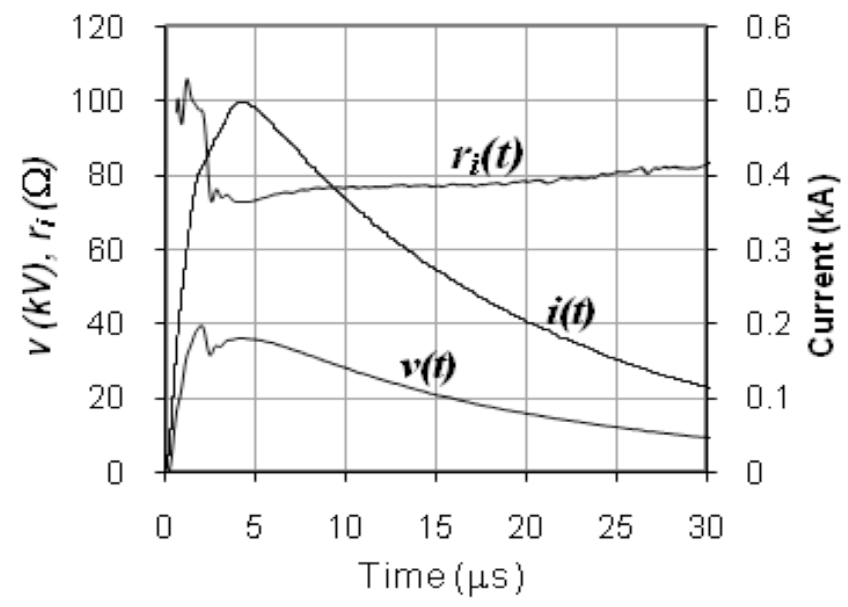

(a)

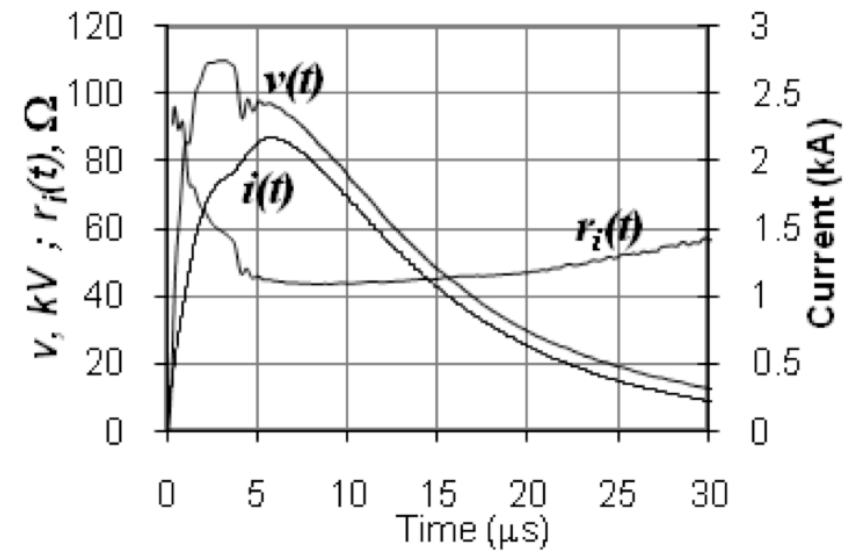

(b)

Fig. (10). Dynamic impulse impedance of tower footing No1. (a) $\mathrm{I}_{\mathrm{p}}=0.5 \mathrm{kA} ;$ (b) $\mathrm{I}_{\mathrm{p}}=2.17 \mathrm{kA}$.

\subsection{Ionization Inception Current}

Soil ionisation occurs at time $t_{i}$ (inception time) and corresponding inception current $I_{i}$. The ionisation inception current was measured at the instant of first current change on the waveshape, and plotted against the rate of rise of current. For simplicity, between the instant of current application and the instant of first ionisation, the mean rate of rise can be assumed as defined by the ratio:

$\frac{\Delta I}{\Delta t}=\frac{I_{i}-i(0)}{t_{i}-0}=\frac{I_{i}}{t_{i}} \quad(k A / \mu s)$

Fig. (12) shows that the first inception current increases linearly with the rate of rise of applied current prior to ionisation. This dynamic property may be important when modelling soil ionisation and should be investigated. In most available models, the inception current or "critical current" is usually taken as a constant independent of time [8]. 


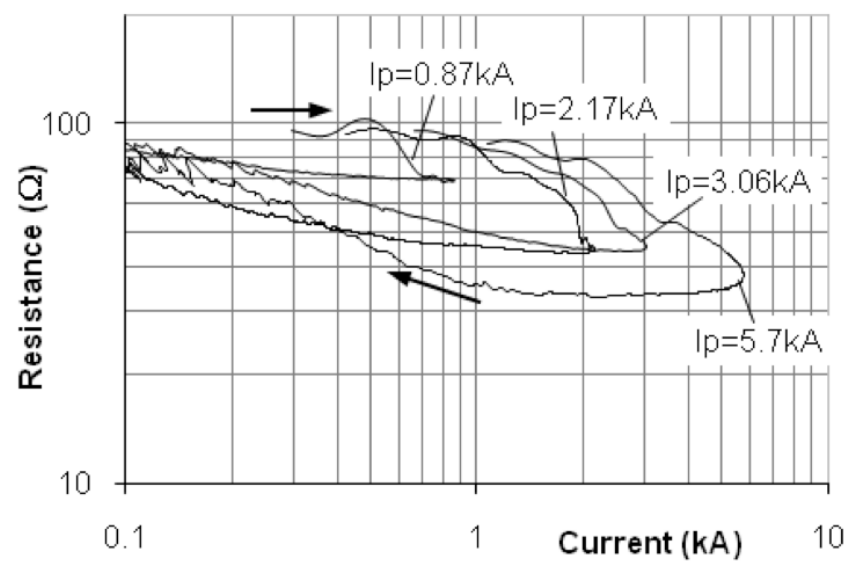

(a)

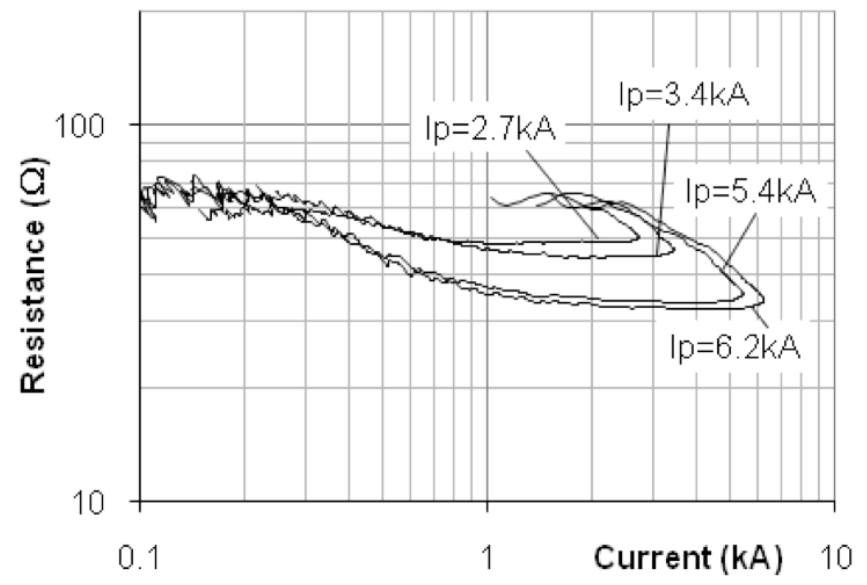

(b)

Fig. (11). Impedance variations with current: (a) tower footing No1, (b) tower footing No3.

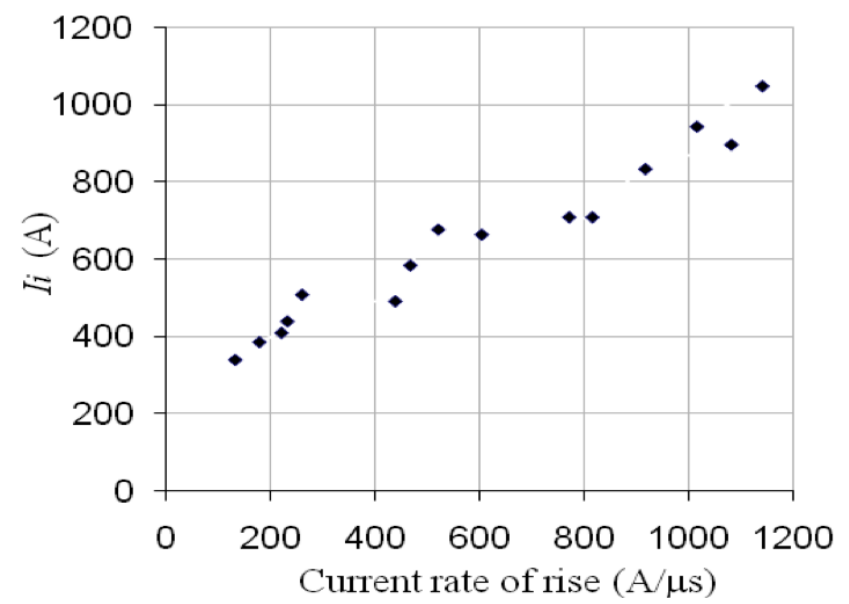

Fig. (12). Relationship between current rate of rise and ionisation current.

\section{MEASUREMENT OF GROUND POTENTIALS}

\subsection{Surface Potential Measurements}

The impulse and AC ground potentials with reference to the $100 \mathrm{~m}$ remote electrode were measured over three surface profiles; two centre profiles (P1, P2) and one diagonal profile (P3), all starting from the tower base centre, as shown in Fig. (2b). The current magnitudes injected in the tower base were $5.8 \mathrm{~A}$ for the $5 / 23 \mu$ s impulse and $4.8 \mathrm{~A}$ for the $\mathrm{AC}$ current. All potentials were normalized to unit current and expressed as a percentage of the tower base ground potential rise (GPR) for comparison. Fig. (13) shows the peak values of the impulse ground potential distributions on the profiles, together with the $50 \mathrm{~Hz}$ rms values along the diagonal profile P3. As can be seen, high potential gradients develop over profile $\mathrm{P} 3$, with a maximum close to the tower footing which is at distance of $5.35 \mathrm{~m}$ from the centre. Over the two centre profiles, the ground potentials are much lower. Along the diagonal profile, the impulse potential drops from $76 \%$ to $20 \%$ of the GPR within a distance of $2.5 \mathrm{~m}$ from the tower footing. The rate of fall of potential is more or less the same either side of the tower footing. Beyond a certain distance, the potential falls much less steeply. The steepness of the impulse ground potential near the tower footing along the critical profile is higher than the AC ground potential. The effect of the ring electrode at $30 \mathrm{~m}$ is seen as small increase in potential on all profiles.

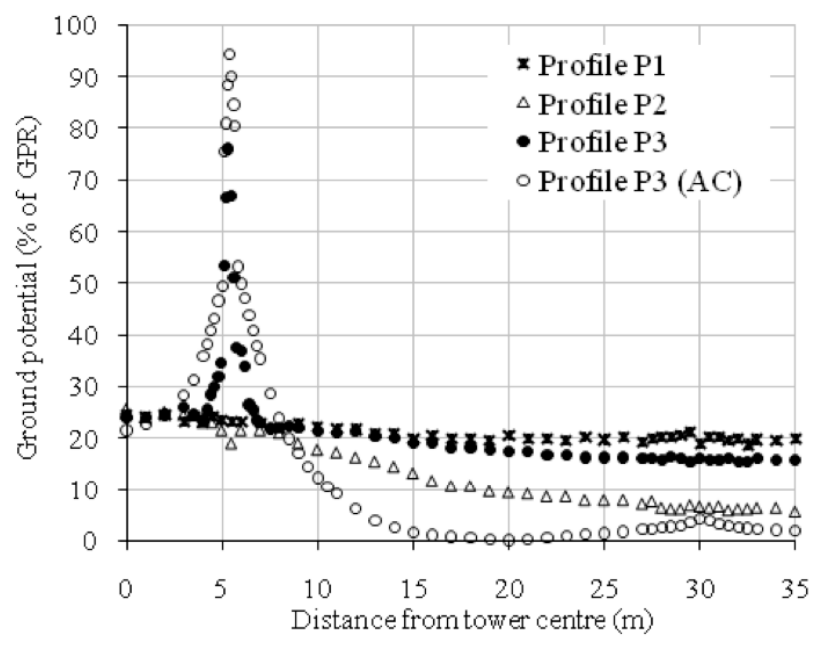

Fig. (13). Distribution of impulse and AC ground potentials over surface profiles.

\subsection{Prospective Touch and Step Voltage Measurements}

Few experimental studies on step and touch voltages at towers and resistive grounds have been reported $[14,15]$. In this work, the physical layout arrangements used for the measurement of touch and step voltages around one of the tower footings (Footing No.4) is shown in Fig. (14). The touch voltages were measured between the tower footing and each of eight points located around a $1 \mathrm{~m}$-diameter circle at angular intervals of $45^{\circ}$. These voltages were acquired in two ways: first indirectly by subtracting the measured ground potential from the GPR using the results of Fig. (7), and second, directly measured using a differential voltage transducer.

Fig. (15) shows the measured touch voltage results as a percentage of the tower base GPR. The prospective touch voltage has approximately the same value for all measurement points.

In general, the impulse touch voltage is higher than the AC touch voltage. For the other tower footings, it was found that the touch voltages were different and depend on the tower footing resistance, with the worst-case touch voltage occurring at tower footing No. 1. The step voltages were 
measured along the diagonal profile only, where the highest voltage gradients occurred. Fig. (16) shows the measurement results. Close to the tower base, the power frequency step voltages are higher than the impulse step voltages, reaching up to $15 \%$ of the GPR on the inner side of the profile. At points beyond $8 \mathrm{~m}$ away from the tower base, the impulse and AC step voltages are practically similar. Both step and touch voltages were found to increase approximately linearly with the magnitude of injected current.

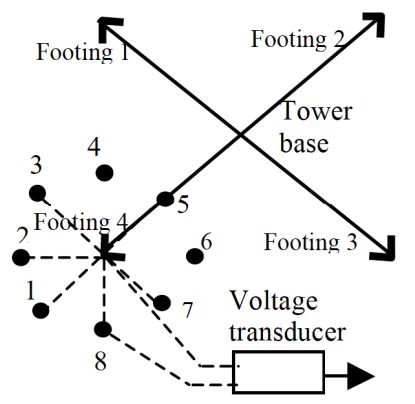

(a)

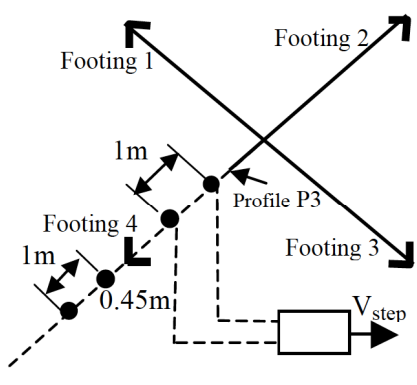

(b)
Fig. (14). Diagram illustrating (a) touch and (b) step voltage measurement methods.

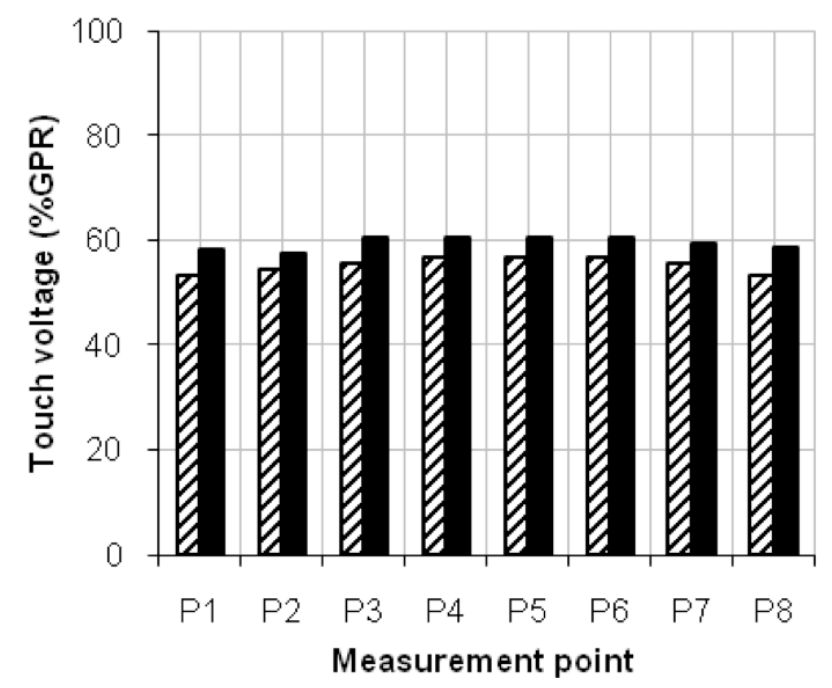

Fig. (15). Measured touch voltage around Leg 4. dashed bars: AC touch voltage.

\subsection{Below-Ground Potential Measurements}

To assess voltage distribution with depth, the ground potential near tower footings at different depths was measured under impulse currents of different rise times and under variable-frequency AC currents. Potential probes buried at $1 \mathrm{~m}, 2 \mathrm{~m}$ and $3 \mathrm{~m}$ depths at a distance of $1 \mathrm{~m}$ away from tower footing No.2 were used to measure belowground potentials $\mathrm{Vg} 1, \mathrm{Vg} 2$ and $\mathrm{Vg} 3$ respectively. Within tower footing No.1, similar probes installed inside the concrete enabled the measurement of concrete potentials $\mathrm{V}_{\mathrm{c} 1}, \mathrm{~V}_{\mathrm{c} 2}$ and $\mathrm{V}_{\mathrm{c}} 3$ at $1 \mathrm{~m}, 2 \mathrm{~m}$ and $3 \mathrm{~m}$ depths respectively. Fig. (17) shows a diagram of the below-ground measurement setup using pre-installed probes and insulated conductors. An example of the below-ground impulse potentials near tower footing No.2 for an impulse current of $5.7 \mu$ s rise time and $1.55 \mathrm{~A}$ magnitude is shown in Fig. (18). The potential at $1 \mathrm{~m}$ depth $(\mathrm{Vg} 1)$ is about $11 \%$ of the tower footing GPR, reducing by a very small amount as depth increases. This indicates that at this distance from the tower footing, the ground potential gradient with depth is small. Table $\mathbf{2}$ shows the peak values of the below-ground impulse potential at different depths and for different current rise times. For the fast impulse current, the measured potential at $3 \mathrm{~m}$ is slightly higher than that at the other depths because of the effect of measuring wire inductance.

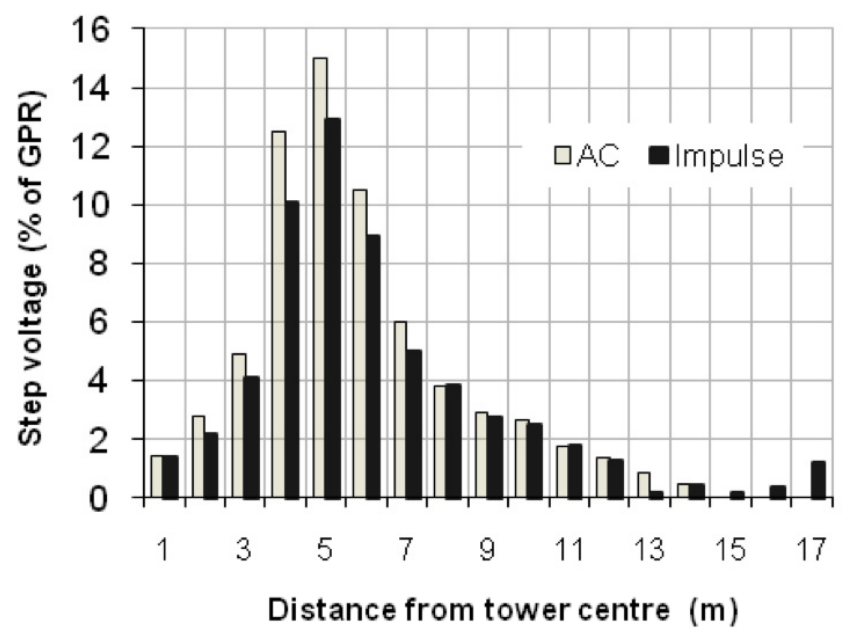

Fig. (16). Measured AC and impulse step voltages.

Similarly, for AC injected current of fixed amplitude, the below-ground potentials in the vicinity of tower footing No. 2 show little variation with depth, as shown in Fig. (19) for the frequency range between $20 \mathrm{~Hz}$ and $120 \mathrm{kHz}$. The concrete potentials inside tower footing No.1 and the tower footing GPR are shown in Fig. (20) for the same frequency range. A more important decrease of concrete potential and GPR with depth and frequency is observed.

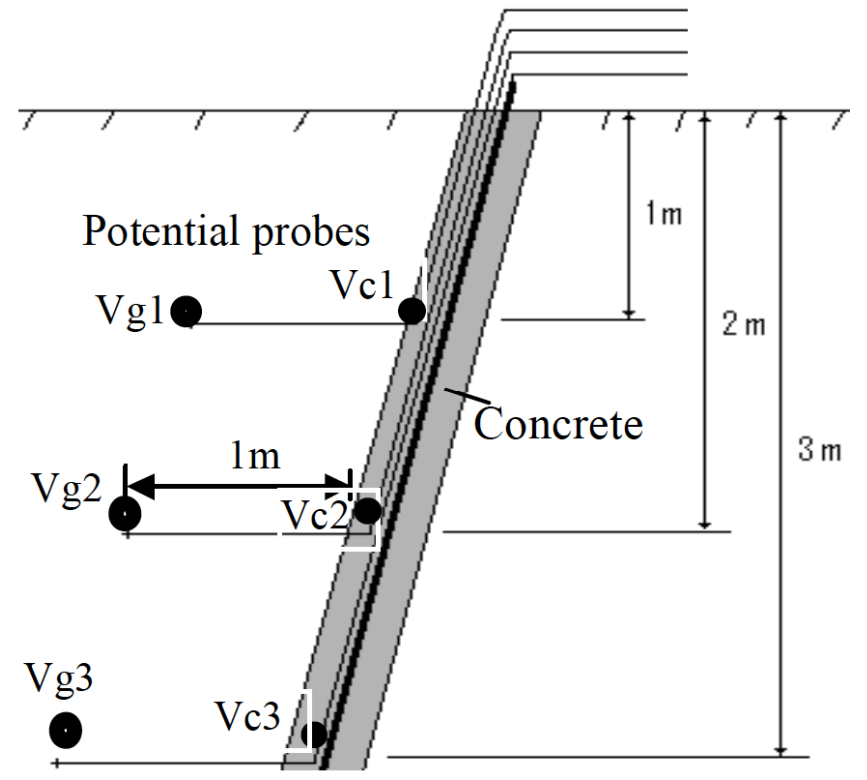

Fig. (17). Below-ground potential measurement.

\section{CONCLUSIONS}

The characteristics of a full scale tower base under impulse currents have been investigated through a series of low-current and high-current impulse tests. For low- 
magnitude currents, the impulse resistances of the tower legs were found to have different values due to differences in localised soil conditions. The dc resistance and impulse resistance of the tower footings were similar and the measured values agreed closely with calculation values. For the high-current impulse tests, the following conclusions can be made:

- $\quad$ The use of a ring electrode allowed the test current to be more evenly distributed around the tower base, compared with the case of a single rod electrode.

- The impulse resistance defined as the ratio of the voltage at the instant of current peak to the peak current is an appropriate parameter for characterizing the impulse behavior of the tower base. The impulse resistance decreases with the magnitude of the impulse current.

- The largest reduction in impulse resistance occurred with the tower footing having the highest DC resistance, but the full tower base showed only a relatively small reduction.

- The time variations of the dynamic impedance showed that at high currents, the ionization was characterized by two reductions in the resistance associated with simultaneous increase in current and reduction in voltage. The time and current dependence of the impulse impedance are therefore important parameters for modeling the performance of grounding systems under high impulse currents.

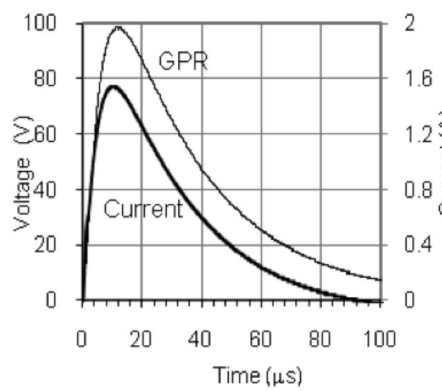

(a) current and GPR

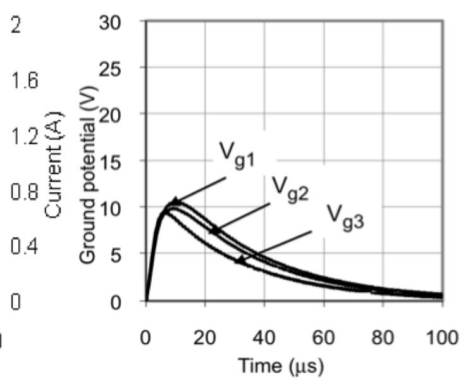

(b) Below-ground potentials
Fig. (18). Example of measured impulse current and corresponding below-ground potentials near tower footing No2, impulse current risetime: $5.7 \mu \mathrm{s}$.

Table 2. Measured Below-Ground Impulse Potentials at Tower Footing No2

\begin{tabular}{|c|c|c|c|}
\hline Current rise time $(\mu \mathrm{s})$ & 3.1 & 5.7 & 7.9 \\
\hline Injected peak current $(\mathrm{A})$ & 1.63 & 1.55 & 1.64 \\
\hline Tower footing GPR $(\mathrm{V})$ & 99.7 & 98.5 & 108.2 \\
\hline $\mathrm{Vg} 1$, peak $(\mathrm{V})$ & 24.1 & 10.6 & 22.6 \\
\hline $\mathrm{Vg} 2$, peak $(\mathrm{V})$ & 23.4 & 9.94 & 20.3 \\
\hline $\mathrm{Vg} 3$, peak $(\mathrm{V})$ & 25 & 9.5 & 17.9 \\
\hline
\end{tabular}

The impulse touch voltage at each tower leg depends on the ground resistance of the individual tower leg. High prospective impulse touch voltages were measured around the tower legs under impulse currents, and these were higher than the power frequency touch voltages. However, the prospective impulse step voltages near the tower leg were lower than the power frequency step voltages. The belowground potential has small values at $1 \mathrm{~m}$ depth and showed little decrease with depth. The concrete potential inside the tower footing, however, showed a more important decrease with depth.

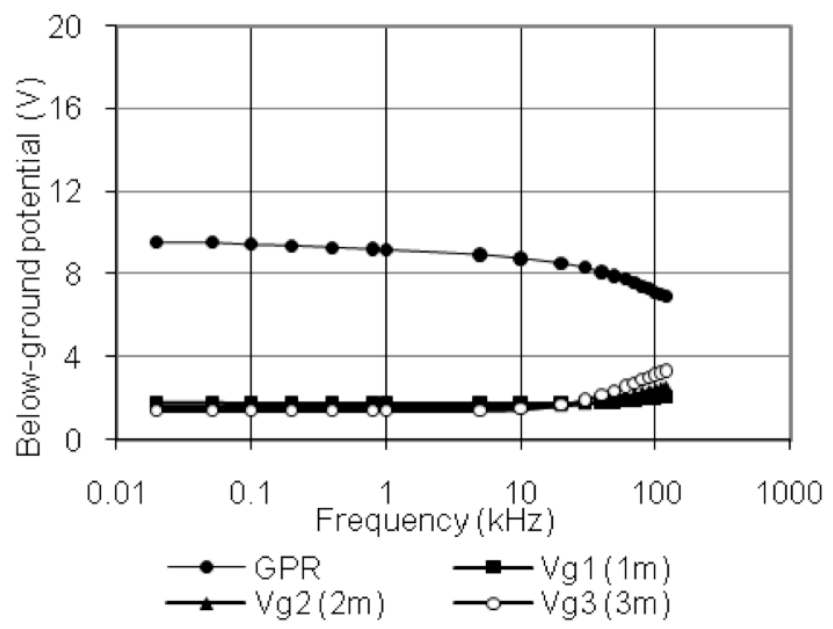

Fig. (19). Below-ground potentials at different depths near tower footing No2.

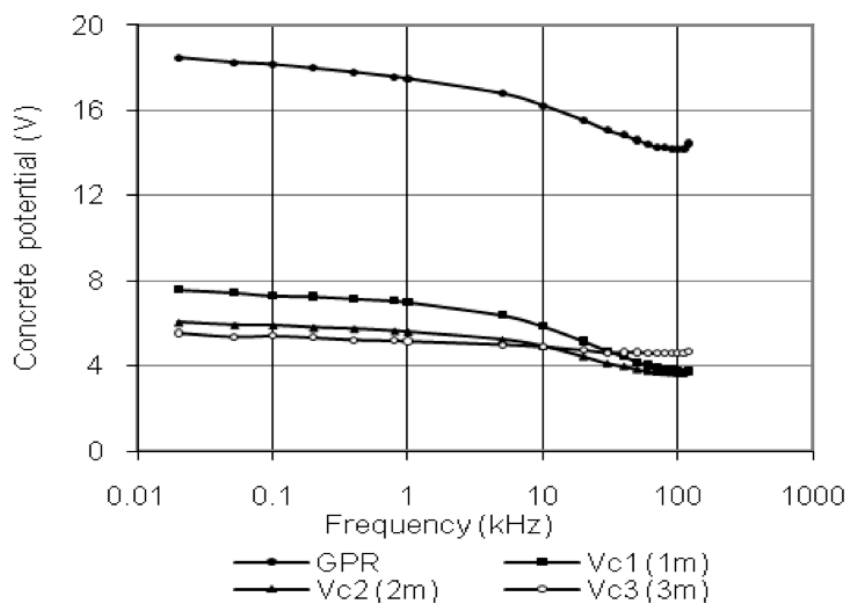

Fig. (20). Concrete potentials at different depths inside tower footing No1.

\section{ACKNOWLEDGEMENTS}

The authors gratefully acknowledge the financial support provided by National Grid for this work.

\section{REFERENCES}

[1] Kosztaluk R, Loboda M, Mukhedkar D. Experimental study of transient ground impedances. IEEE Trans Power Appl Syst 1981; 100(11): 4653-60.

[2] Sekioka S, Hayashida H, Hara T, Ametani A. Measurement of grounding resistances for high impulse currents. IEEE Proc Gener Trans Distrib 1998; 6: 693-99.

[3] Takeushi M, Yasuda Y, Fukuzono H, et al. Impulse characteristics of a $500 \mathrm{kv}$ transmission tower footing base with various grounding electrodes. Int Conf on Lightning Protection ICLP-98. Birmingham, UK. 1998; vol. 1: pp. 513-7.

[4] Harid N, Zanini A, Griffiths H, Haddad A. Characterisation of tower base earthing systems under impulse conditions. $27^{\text {th }}$ Int conference on Lightning Protection. 13-16th September 2004, France: Paper 5.A2, p. 4.

[5] Bendjamin J, Haddad A, Harid N, Griffiths H, Ainsley A. Highmagnitude current impulse tests on $275 \mathrm{kV}$ transmission tower base. 
International symposium on high voltage engineering. University of Ljubljana, Slovenia, 2, Paper T2-433, 2007.

[6] He J, Zeng R, Tu Y, Zou J, Chen S. Laboratory investigation of impulse characteristics of transmission tower grounding devices. IEEE Trans Power Deliv 2003; 18(3): 994-1001.

[7] Korsunscev AV. Application of the theory of similitude to the calculation of surge characteristics of concentrated earth electrodes. Elektrichestvo 1958; 5: 31-5.

[8] Liew AC, Darveniza M. Dynamic model of impulse characteristics of concentrated earths. Proc IEE 1974; 121(2): 123-35.

[9] Velazquez R, Mukhedkar D. Analytical modelling of grounding electrodes transient behaviour. IEEE Trans Power Appl Syst 1984; 1039(6): 1314-22.

[10] Mousa AM. The soil ionisation gradient associated with discharge of high currents into concentrated electrodes. IEEE Trans PWRD 1994; 9(3): 1669-77.
[11] Sekioka S, Lorentzou MI, Philippakou MP, Prousalidis MJ. Current-dependent grounding resistance model based on energy balance of soil ionisation. IEEE Trans Power Deliv 2006; 21(1): 194-201.

[12] Dawalibi FP, Donoso F. Integrated Analysis Software for Grounding, EMF and EMI. IEEE Comput Appl Power 1993; 6(2): 19-24.

[13] Tagg GF. Earth Resistances. New York: Pitman 1964.

[14] Cherney EA, Ringler KG, Kolcio N, Bell GK. Step and touch potentials at faulted transmission towers. IEEE Trans 1981; 100(7): 3312-21.

[15] Nayel M, Zhao J, He J, Cai Z, Wang Q. Study of step and touch voltages in resistive/capacitive ground due to lightning stroke. 4th Asia-Pacific Conference on Environmental Electromagnetic (CEEM'2006), Dalian, China, August 2006; vol. 2: pp. 1-7.

Received: November 5, 2010

Revised: February 2, 2011

Accepted: February 18, 2011

(c) Harid et al.; Licensee Bentham Open.

This is an open access article licensed under the terms of the Creative Commons Attribution Non-Commercial License (http://creativecommons.org/licenses/by-nc/3.0/) which permits unrestricted, non-commercial use, distribution and reproduction in any medium, provided the work is properly cited. 